Studia UBB 刃⿴囗十)igitalia, Volume 63 (LXIII) 2018, December, Issue 2, 19-30

Published Online: 2018-12-30

DOI:10.24193/subbdigitalia.2018.2.02

\title{
The use of relational databases in epigraphy: a case study
}

\author{
Silvia Gazzoli \\ Università degli Studi di Milano
}

\begin{abstract}
The study of an abundant number of inscriptions leads to the conception of schemas and forms that can be organized into databases. This procedure allows us to arrange information with precision and to draw data and create connections between them in quickly and easily. For this reason, the relational database model has proved to be a valid support, as it makes possible to arrange data and information logically according to pre-established constraints and relationships, reducing errors and repetitions. The aim of this paper is to present an example of the use of a relational database created to catalogue inscriptions and highlight the positive aspects and difficulties found out during the process. The complexity of this method is mostly related to making choices about entities and identifying relationships between them; another obstacle is connected to the complexity of inscriptions as group of words and formulae. Nevertheless, the relational database allows the researcher to mix up data and information and create new relationships between them using SQL operators. The software used for the case study that will be presented in this paper is an open source administration and development platform pgAdmin (for PostgreSQL).
\end{abstract}

Keywords: epigraphy, inscriptions, database, open source

\section{Introduction}

The aim of this paper is to present a case study related to a research project regarding infant mortality in Northern Italy during Roman Times based on inscriptions and archaeological evidences (The case study presented in this paper is part of the $\mathrm{PhD}$ project "La mortalità infantile in Italia Settentrionale in epoca Romana. II contributo 
della documentazione epigrafica ed archeologica"). The implementation of the project could represent an example for the use of open source relational databases in the context of historical and epigraphic researches. The use of an RDBMS could also be interesting in this particular field due to a simpler and more organized management of the documents listed in the catalogue.

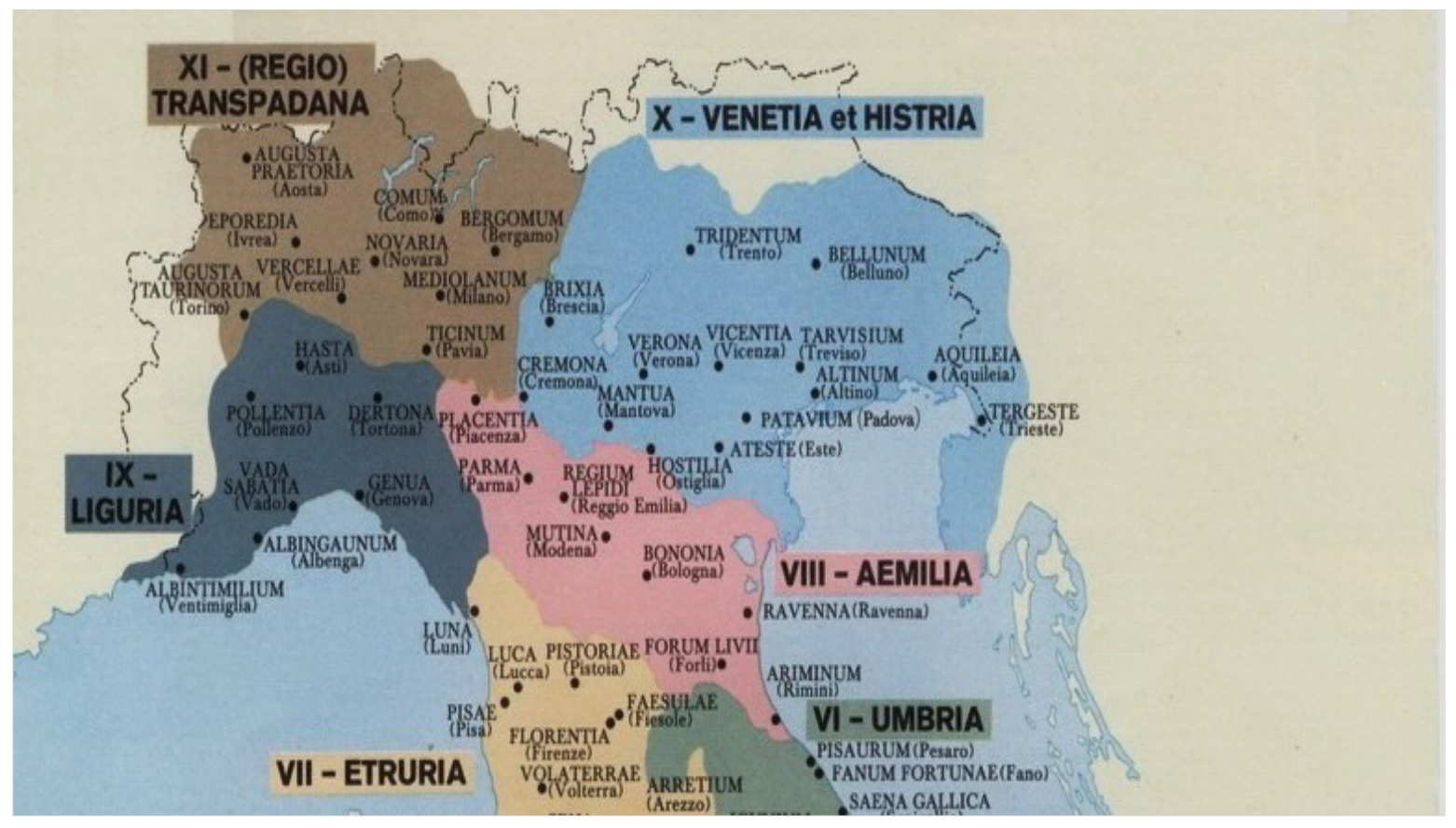

Fig. 1. Map of the Regiones (Augustean Regions) cited, from www.stilus.nl (modified by the author)

The study of several hundred inscriptions belonging to a well-defined topographical context, as the Roman region called Cisalpina (corresponding to today's Italian region Friuli Venezia Giulia, Veneto, Trentino Alto Adige, Lombardia, part of the Emilia, Piemonte, Liguria and Valle d'Aosta) during a period of time that starts from the so called "Romanisation", a sort of transition phase that took place in this area from the second half of the first century B.C., to the end of the Western Roman Empire in the late Vth century A.D., leaded to the creation of a catalogue. Later a database was conceived to organize and manage inscriptions and archaeological finds related to infant mortality (This project also includes the georeferencing of archaeological and epigraphic evidences through the use of the open-source software QuantumGIS. Methodological reflections and cases studies were presented at two Archeofoss/GFoss conferences in Cagliari 2017 and Rome 2018). 
The introduction of the use of the RDBMS for a simpler management of the epigraphic and, more generally, historical data was more complex than expected. Although, this way of organising and georeferencing information, is frequently used for storing archaeological finds (Fronza 2000; Fronza 2003; Fronza 2009; Anichini et alii 2002), it has rarely been used in connection with historical and epigraphic documentation.

\section{The epigraphic evidence: an overview on heterogeneous documents}

The first fundamental step is the definition of the characteristics of the data to be listed and organised within the database. Latin inscriptions, particularly epitaphs, represent a well recognizable group of documents usually defined by recurring phrasal structures, constructions and formulae. However, many of the inscriptions studied present some variables in the text, or differences in the structure, mainly due to the wide chronological period and the topographical distance that could exist between some of these documents. Other dissimilarities could related to the funeral rituals often mentioned or suggested in the epitaph (in a few epitaphs the noun "ossa" is mentioned, which is probably related to the funeral ritual of cremation and it consequently indicates the ashes preserved in the ossuary; in only one document listed in the catalogue the specific term "cineres" is cited which also referring to this practice, see also Scaletta, EDR140804). Some of these differences, such as the absence of formulae or the presence of variations, are essential from an epigraphic point of view and need to be highlighted in the database. Interesting considerations regarding these evidences can be supported using three epitaphs as examples: these documents are related to various chronological periods and to different sites of provenance but are all connected to the main topic of this research, that is to infant mortality. The first one, from the famous Roman city of Aquileia, has been found inscribed on an ossuary and belonged to III C. B.C. "Sabini / ann(orum) X" (Inscription from Aquileia, CIL V, 8450, also listed in the Ubi erat Lupa online catalogue, no. 16123). In this short epitaph the information is scarce and limited to the name of the deceased (in the genitive case), Sabinus, and not too accurate biometric data, as it only specifies that he lived for ten years. The age of the child is not stated with the usual formula: "qui/quae vixit" (Di Stefano Manzella 1987 223-224) followed by precise indications of the years, months and days lived, but it is more concise.

The second epitaph was found in Visinada, in Istria (Croatia) and was dedicated to a young boy, named Florentinus, by his parents, Eutyches and Successa: " $D$ (is) M(anibus) / Florentino / annorum VIII[I] / parentes fe/cerunt Euty/[ch]es et Successa" (EDR134214 by V. Zovic, 10/12/2013). After the adprecatio to the Manes, the epitaph 
cited the name of the young deceased, Florentinus (probably a diminutive of the name Florentius), the years lived before death and the names of both the parents. A third example of funeral inscription regarding a child, in this case a girl, was found in the city of Alba, near Cuneo in Piemonte "Castriciae / Saturninae fil(iae) / vixit ann(os) VI ((semis)) / P(ublius) Castricius Saturnin(us) / pat(er) mag(ister) Aug(ustalis) Polle[t(iae)] / Aug(usta) Bagienn(orum) sibi e[t] / Mettiae Paulin[ae] / uxori optim[ae]" (Inscription from Alba, Cuneo, Scheda EDR081081 by L. Lastrico, 24/09/2007). This text is very interesting due to the structure of the epitaph and the information given regarding the social status of this family (Mosca 1957, 8). The first line gives the name of the deceased, Castricia Saturnina, who lived for six and a half years (semis) and who was the daughter of Publius Castricius Saturninus (who was magister Augustalis of Pollentia in Augusta Bagiennorum) and Mettia Paulina.

A very important factor is represented by the presence of formulae, which are a characteristic of funeral epigraphy: these parts of sentences can be easily schematized thanks to their uniformity and repetitiveness. However, they also display copious variables (probably related to local customs, chorological trends or mistakes) that can represent a problem during the data input phase. An example could be the adprecatio to Manes (the Dis Manibus initial sentence): this formula is highly documented not only in the area that was studied in this project, but in the whole Roman Empire, and for a very long period. It is possible to spot some variations in this introduction to the epitaph, such as Dis Manibus, D(is) Manibus, D(is) M(anibus), Dis Manibus Sacrum, D(is) M(anibus) S(acrum), not considering mistakes made by the scriptor or blanks caused by damage in the surface material used. A second example of the use of formulae in the firs lines of epitaphs is related to the consecration of the monument to Memory, Bona Memoria, in order to preserve the memory of the deceased. The sequence of words used to dedicate funeral monuments to this particular deity could be: Bona Memoria, B(ona) M(emoria) or (Bona) Memoria. In general, in the whole catalogue, six different opening formulae were found, with corresponding variations (Raepsaet-Charlier 2002).

Thus, remaining in the context of the conventional parts of the epitaph, as was probably already evident from the proposed examples and from the topic of this research, it is extremely important to pay attention to the methods used to provide information regarding the biometric data, and therefore to the duration of life of the deceased. In this case, six additional expressions were found, not only characterized by formulae, but also using variations of the grammar complement related to age. The canonical expression qui/quae vixit followed by the specification of year, month and day, is often replaced with the genitive of age, constructs of the verb "ago", adjectives, such as anniculus, (Neraudau 1984) nouns and participle followed by different cases. 
There are also various syntactic constructions used for the expression of the date of death or burial, widely used in contexts of Christian religion, but also the indications relating to the place of burial of the ashes, or of the corpse itself of the deceased.

In various inscriptions some iconographical elements can be found in the area of the epitaph, so in strict relationship with the text, that can be essential for dating the document or including it in a particular religious context. Regarding the decoration of the text, an extremely important element that deserves to be mentioned in the catalogue is the so called "hedera distinguens", that can contribute to the identification of the possible date given its chronologically limited use. The iconographic endowment of an inscription from the Christian era is much richer; the text of the epitaph is often interspersed with symbolic elements such as Christograms, representations of animals like fish or birds, images related to the phases of life of a Christian (e.g. representations of christening) and to the religion itself.

The epigraphic document consists not only of the text, that is the inscription, but also of the iconographic set and of the artefact that constitutes the surface material used, that could be a stone, or an object of small dimensions. Funeral inscriptions can usually be found written on different kinds of surfaces: they can be made of local stone or polished marble, or of other kind of objects like roof tiles and amphorae. The study of the material, usually, does not usually provides information related to dating the monument and the inscription, except in some special cases, but it allows us to draw hypotheses regarding the economic, commercial and productive context of provenance. In fact, evidence regarding the material used to fabricate the monument is fundamental, not only when it comes to imported Greek marble, but also when it is possible to identify local lithotypes or stones from excavated areas close to the place of discovery.

Among the most attested surface material discussed in this paper, are certainly stelae, found both in marble and in local limestone, memorial stones, altars and ossuary. On the other hand, sarcophagi, bases and block are less common, although still present. In addition, reused materials have been found: although it is difficult to propose hypotheses on the original nature of these, in the light of the completeness of the study this evidence must still be mentioned.

In addition, the surface material can be covered with an extremely elaborate iconographic apparatus, often, but not always, in connection with the text of the funeral inscription. In the documentation gathered in the catalogue stelae are listed which are decorated with images of children, alone or with their families. In several cases, it was also possible to identify iconographies related to funereal symbology, such as animals (e.g. peacocks) or plants and fruits (e.g. pomegranates) connected to the underworld and to eternal life. 
Several inscriptions turn out to have been lost; information about some of these are kept only thanks to the Corpus Inscritionum Latinarum, so they are, except in rare cases, devoid of images, descriptions or detailed studies related to the ductus or to the surface used. Others, on the other hand, have been found and studied in more recent times but unfortunately have been lost or researched without providing any results (it is not unusual to find in contemporary digital catalogues the Latin formula frustra quaesivi in the field dedicated to the place of conservation) during updates of the catalogues or collections. An example of an epitaph listed in the Corpus but gone missing could be number 3172 from CIL V: the document found in the vicinity of the modern city of Vicenza, consisted of an epitaph regarding a boy named Fortunius who died at the age of 3 years, 7 months and 6 days " $D$ (is) $M$ (anibus) / Fortunio / filio karissi/mo q(ui) vi(xit) an/n(is) III m(ensibus) VII d(iebus) VI / parentes pientissimi I $v$ (ivi) f(ecerunt)" and a very interesting decoration. The distinctive trait lies in the description provided by the author of the CIL profile, which shows the presence of a decorative apparatus both after the adprecatio formula with a protome (maybe a child image?) and at the end of the text. This last depiction is described with the following words "puer stans ante eum pavo", so there was probably an image of a child with a peacock in front of him. (CIL V, 3172).

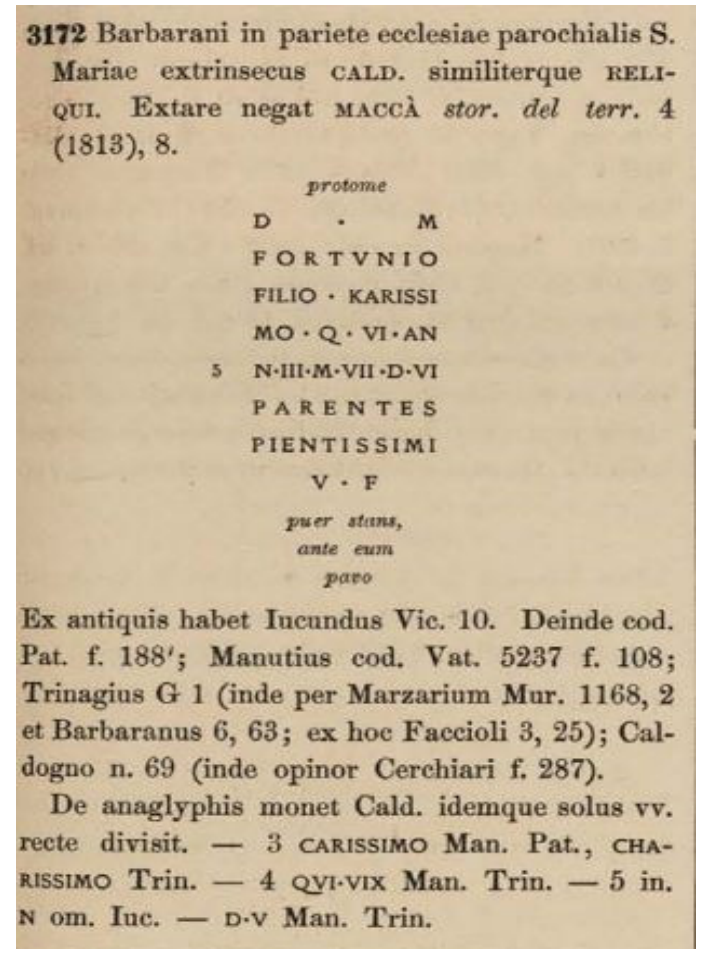

Fig. 2. Picture of the epitaph's form in the Corpus Inscriptionum Latinarum (picture by the author) 


\section{Methodological issues and possible solutions}

The mass of materials briefly described above leads the scheduler to pose questions about the nature and the characteristics of the most suitable database for the storage and the consequent fruition of the data. A first hypothesis, certainly simpler in its realisation, could be the creation of a single table with each line corresponding to an inscription and each column containing a particular characteristic or a piece of information. This first and simpler option, however, although it may seem more manageable in case of further and subsequent changes, does not ensure adequate control over possible typing error, and would allow a limited use of data without being able to propose particular functions. A second option was the creation of an EntityRelationship Model Database, both realizing the Logical and Conceptual models in the design phase and developing the data structure. The opportunities offered by this type of database are unlimited, both from the data storage point of view and from the possible use of the information listed through the various functions offered by the SQL languages. A further point in favour of choosing an entity-relationship database is the reduced percentage of errors obtained by compiling firstly the slave tables and then inserting information into the master ones through the closed selection deriving from the relationships between them.

However, this precautionary design phase highlighted some methodological problems that also reflected on the setting of the extended catalogue, leading to some changes in the form's structure that subsequently became necessary.

The first problem to highlight is related to the place where the inscription was found: when the evidence was discovered during an archaeological excavation or circumstances that allowed its exact topographical registration, this information is considered reliable and it is inserted in the catalogue's form. Conversely, several epitaphs have passed through private collections before arriving in the museums where they are now stored. In these cases, some data, especially that regarding the site where the document has been found, has been lost. This can therefore not be included in the relative form, or database table, requiring the creation of a new entity for the database regarding only the location of the various collections mentioned in the catalogue and the information provided by their registers. Likewise, it was necessary to create a table related to the inscriptions on re-used material and only afterward exhibited in museums. Even in this case important information regarding the original discovery site was lost and the place of reuse could not be included as the place of discovery because it would be a methodological error (not only related to the database but to the study of the monument itself). To compensate for this problem 
in the structure of the database, an additional table has been added for re-used materials in order to store information as accurately as possible about these documents. The data regarding the discovery, therefore, can be inserted into a textual field that does not provide the NULL value to avoid a compilation error, but rather uses the word ignoratur (not known) in cases of lack of information, or even better the definition "re-used document" that would then lead to its slave entity.

The second problem is related to the very same inscriptions: from the concise examples provided in the previous paragraphs it is possible to understand how the document studied, catalogued and on their way to being inserted into the database, are extremely different both as regards the presence of formulae, or not, and for the length of the text (an example is the inscription of Lucius Trebius Divus, see Zoia 2015, EDR124801). Firstly it was proposed to create a subdivision of the text into parts, thus highlighting the formulae or opening lines of the inscription, then a second section dedicated to memory, to underline words used to remember the young deceased, and to the dedication, a third for the biometric data and a fourth for the closing lines of the epitaph with formulae or the call to the reader. Yet, there are only a few documents that fully reflect this pattern. Certainly, inscriptions on ossuaries distance themselves from this structure as they bear much more concise information, and at the same time some stelae or tabulae are accompanied by extremely complex texts. In addition, several inscriptions not only report the memory of the young deceased, but also associate him or her with other characters, still alive, already dead or deceased in the same period (ILCV 847 = Novillo Lopez 2014, EDR139687). It would be very difficult to include these cases in the previously proposed schema, because it would probably lead to the loss of some information or to risk falling into errors, distorting meanings or underestimating the importance of certain data.

A further problem brought by the choice of this option would be to lose the unity of the text, favouring only some of its parts. For this reason, a second option was chosen, perhaps more complex from the implementation point of view, and, unfortunately, more prone to the production of possible errors, but at the same time it is the most common for other on-line database used for storing and sharing inscriptions. It consists of the creation of a field, called testo_iscrizione (text_inscription), with very few restrictions and a practically indefinite length, in text form, with the impossibility of the NULL option, for the transcription of the entire inscription accompanied by terminations. In this way the text is not partitioned or restricted within tables that are excessively rigid, but there is still a high percentage of possible error for the compiler, who therefore must list text without the possibility of retrieving data from the slave tables usually offered by this type of database. 
It is therefore right to propose some considerations regarding methods of carrying out research or activating selections and functions working with text fields of variable length and in the absence of further references. To try to overcome this problem Boolean fields were inserted (that is containing only the true/false possible values) followed by a further field, with "nullable" definition, with the specification of what was previously briefly reported. For example, while inserting in the database information about the above-mentioned inscription regarding Sabinus, in the field concerning the presence of an opening formula it is enough to reply by leaving the relative square empty (so the Boolean answer is "false") and consequently not filling in the following field. Otherwise, in the case of the inscription in memory of Florentinus, the compiler would cross the square (as the answer is "true") and then in the following field specify from the cascade menu the presence of the adprecatio to the Manes. This relationship between two tables could lead to further information in the related table concerning opening formulas, where chronologies and detailed studies are listed.

The presence of columns with stringent limitations, such as Boolean fields, allows us to structure relationships between tables to take advantage of the flexibility offered by the relational database.

As we have seen, the inscriptions studied in this project, contain a large amount of information and the peril of losing them, or making them difficult to use, represents the most feared risk of this work. Some of this data are related to the young deceased, whose memory is preserved only in these documents. Until now this paper was focused on the possible options to schematize or summarise inscriptions' texts, analysing problems related to formulae, length of the epitaph, sites of discovery. A more important element concerns the people mentioned in the epitaphs; this project does not concentrate only on studying inscriptions from a precise topographical area but also is related to archaeological evidences and demographical considerations. For this reason, it was also necessary to hypothesize a way of creating connections between tables/entities concerning inscriptions with the ones related to the deceased children mentioned in it. In order to be useful for the research, these tables have to contain information about biometric data, families, social status and, when possible, provenance.

The unifying element of all these evidences can not be the catalogue number of the single inscription; although, it connects both the epigraphic text and the children mentioned in it, and all the information regarding surface material used, place of discovery and museum where the inscription is preserved, in several inscriptions more than one child is mentioned. The choice for the primal key, then, must therefore fall on an automatic identifier that allows the identification of every individual deceased. Given the different possibilities offered by the epitaphs regarding the explication of 
the biometric data, and consequently, of the children's age at the time of death, a table has been created called "gruppi_eta" (age_group). In this entity groups are listed which, based on the information provided by literary and legal sources relating to childhood, allow us to include the range of options mentioned in the inscriptions.

Referring to the most famous authors and taking up what was written by Neraudau (Neraudau 1984) in his famous contribution on Childhood in the Greek and Roman world, the life of a Roman was marked by several passages, especially when he was young. According to Varro, the stage called "pueritia" consisted of a long period that ranged from birth to the age of 15 , ideally when the puer became an adult. On the other hand, the articulation of passages described by Isidoro from Siviglia provides a narrowed periodization, which consist of infantia (from birth to the age of 7), the subsequent pueritia (up to 14 years old) and in the adulescentia, that ended at the age of 28 years. However, according to the modern literature on the subject (Laes 2011), the steps that marked childhood and continued until the age of maturity were much denser, especially in the Roman world. For this reason, and to avoid the repetition of data already filed in entities regarding epitaphs, these "age groups" reflect as much as possible the stages of growth and at the same time allow a greater schematization of the evidences provided. The first group goes from birth to three years old; as reported by ancient sources at this age there was the end of breastfeeding and the beginning of weaning. The second one goes from three to seven years old. At this age there was a sort of "social division by gender" the young males started to go to school and live outside the house, while young females were introduced to domestic activities along with the other women of the family. The last group goes until the age of twelve for the girls: at this age puberty has usually started and sexual maturation was one of the requisites for legal marriage. For young boys adulthood had not a precise starting point related to physical maturation, but they usually changed the toga at the age of 15 , so this is the upper limit for the last age group. Thanks to these clusters, which were included in a table, it was possible to synthesise biometric information provided in the inscription in order to carry out demographic and social studies without having to limit data due to schematization.

\section{The Software}

During the design phase of the database's structure was chosen an open source product that would easily allow interfacing with the georeferencing open source software that is most commonly used in the archaeological field, that is QuantumGIS (https://qgis.org/en/site/). This program itself provides several plugins in order to facilitate 
the creation of a database to storage information related to georeferenced data and one of this is a connection to a PostgreSQL (https://www.postgresql.org/) database. Although several university projects are based on the use of proprietary software, such as ArcGis for the georeferentiation and Microsoft Access for the database (Anichini, Paribeni 2005), for this research open programs were chosen, in order to enhance the increasing attention given to the open source movement.

PostgreSQL represent a very interesting object-related database system that is based on SQL language and has more than 30 years of active development so its use can be supported by a good amount of documentation and by a careful and active community of users and developers. For a better and easier use of PostgreSQL and to facilitate the future connection with QuantumGIS a graphical administration tool was selected, the most highly recommended one, PgAdmin (https://www.pgadmin.org/).

\section{The outlook}

While the physical structuring phase of the database is still in progress, some tests were carried out to identify possible problems with the insertion of data and their subsequent use. The employment of preparatory schemes and the preliminary organisation of tables and columns' constraints, as mentioned before, allowed us to highlight some problems that only partially have found a solution. This work-in-progress project is highlighting how the use of relational databases, widely attested in other similar disciplines like archaeology, represent a challenge in the epigraphic field, especially when dealing with complex researches and not only with the simple cataloguing of inscriptions. The aim of this project, and therefore of this paper, is to present and develop a database that allows both the listing of epigraphic documents in the most accurate way possible, and the highlighting of the content of the texts studied thanks to different tables. The possibility of underlining the relationships between the people mentioned in the epitaphs, their possible status within the community of origin, together with the georeferencing of the documents could represent a new possibility of work for epigraphic projects linked to small or medium sized regions.

\section{Works Cited}

Anichini, Francesca; Fabiani, Fabio; Gattiglia, Gabriele, Gualandi Maria Letizia, "Un database per la registrazione e l'analisi dei dati archeologici”, in MapPapers 1 - II, 2012, 1-20. 
Anichini, Francesca and Paribeni Emanuela, "Il Gis archeologico della città di Pisa. Primi risultati per la tutela e la gestione del patrimonio archeologico pisano" Notiziario della Soprintendenza archeologica della Toscana, 1, 2005, 205-210.

Di Stefano Manzella, Ivan. II mestiere di epigrafista: guida alla schedatura del materiale epigrafico lapideo. Quasar, Roma 1987.

Fronza, Vittorio, "II Sistema di gestione degli archivi nello scavo di Poggio Imperiale a Poggibonsi. Una soluzione all'interno della soluzione GIS", Archeologia e Calcolatori, 11, 2000, 125137.

Fronza, Vittorio, "Principi di database management in archeologia: l'esperienza senese" III Congresso Nazionale di Archeologia Medievale edited by Fiorillo R., Peduto P., All'insegna del Giglio, Firenze, 2003, $629-632$.

Fronza, Vittorio "L'archiviazione del dato in archeologia", Informatica e Archeologia Medievale. L'esperienza Senese edited by in Fronza V, Nardini A., Valenti M., All'insegna del Giglio, Firenze, 2009, 1-15.

Laes, Christian. Children in the Roman Empire. Outsiders Within, Cambridge University Press, Cambridge 2011.

Mosca, Edoardo. Le epigrafi del Museo di Storia e d'Arte di Bra, SASTE, Bra, 1957.

Neraudau, Jean-Pierre. Etre enfant à Rome, coll. Realia, Les Belle Lettres, Paris, 1994.

Raepsaet-Charlier Marie-Therese. Hic situs est ou Dis Manibus. Du bon usage de la prodence dans la datation des épitaphes gallo-romaines in L'antiquité classique, vol. 71, 2002, 221-227.

\section{Inscriptions Cited}

Scheda EDR140804 by C. Scaletta $(11 / 14 / 2015)=$ CIL V $2417=$ CLE 1157 (Found in Ferrara, dated in the half I c. A.D.)

Scheda EDR134214 by V. Zovic $(10 / 12 / 2013)=$ CIL V, 8195 (Found in Visinada/Vizinada, date unknown)

Scheda EDR139094 by M. A. Novillo Lopez (18/08/2014) = Brusin 1993, nr. 3214 (Found in Aquileia, IV c. A.D.)

Scheda EDR139687 by M.A. Novillo Lopez (22/07/2014) = ILCV 847 (Found in Aquileia, IV c. A.D.)

Scheda EDR146314 by C. Girardi /11/01/2015) = CIL V, 3172 (Found in Vicenza, date unknown)

Scheda EDR124801 by S. Zoia (23/02/2015) (Found in Milan, III- IV c. A.D.)

Scheda EDR081081 by L. Lastrico (24/09/2007) = CIL V, $7604=$ ILS 6749 (Found in Alba, II c. A.D.)

CIL V, $8450=$ EDCS01601269 = Ubi Erat Lupa nr. 16123 (Found in Aquileia, date unknown) 
Studia UBB 㚼igitalia, Volume 63 (LXIII) 2018, December, Issue 2, 19-30

Published Online: 2018-12-30

DOI:10.24193/subbdigitalia.2018.2.02 